\title{
UJI EFEK ANALGETIK DAN ANTIINFLAMASI EKSTRAK ETANOL 70\% DAUN BERUWAS LAUT (Scaevola taccada (Gaertn.) Roxb.) PADA TIKUS PUTIH (Rattus novergicus)
}

\author{
Amran Nur ${ }^{*}$, Dedi Ma'ruf ${ }^{* *}$, Ira Widya Sari**), Natsir Djide ${ }^{* * *)}$, Peter Kabo****) \\ ${ }^{*}$ Mahasiswa Farmakologi, Biomedik, Universitas Hasanuddin \\ (email : amrannur70@gmail.com ) \\ ${ }^{* *}$ Bagian Farmasi, Prodi D III Farmasi, STIKES Pelamonia Kesdam VII Wirabuana. \\ (email: himadipo@gmail.com) \\ ${ }^{* *}$ Bagian Farmasi, Prodi D III Farmasi, STIKES Pelamonia Kesdam VII Wirabuana \\ (email: irha widyasari@yahoo.com) \\ ${ }^{* * *}$ Bagian Farmasi, Fakultas Farmasi, Universitas Hasanuddin \\ (email : natsirdj@yahoo.com) \\ ****).Bagian Farmakologi, Fakultas Kedokteran, Universitas Hasanuddin \\ (Email : peterkabo_fkuh@gmail.com)
}

\author{
Alamat Korespondensi: \\ Amran Nur \\ HP. 085299931023 \\ Email: amrannur70@gmail.com
}

\section{ABSTRAK}

Uji efek analgetik dan antiinflamasi ekstrak etanol $70 \%$ daun beruwas laut (Sacevola taccada. Gartn.) Roxb) terhadap Tikus Putih (Rattus norvegicus) Jantan. Penelitian ini bertujuan menentukan efek analgetik dan antiinflamasi esktrak etanol 70\% daun beruwas laut (Sacevola taccada. Gartn.) Roxb) terhadap Tikus Putih (Rattus norvegicus) Jantan. Penelitian ini adalah penelitian eksperimental dengan pendekatan pre dan post test control group design. Sampel dibagi dalam 6 kelompok, yaitu kelompok normal, kontrol negatif, kontrol positif, dan kelompok ekstrak. Pada kelompok ekstrak, menggunakan 3 dosis ekstrak yang berbeda yaitu ekstrak dosis 12,5 $\mathrm{mg} / \mathrm{kgBB}, 25 \mathrm{mg} / \mathrm{kgBB}$, dan 37,5 mg/kgBB. Penentuan analgetik dengan metode Writhing test yang diinduksi dengan asam asetat $1 \%$ sedangkan antiinflamasi dengan pembentukan edema buatan dengan penginduksi karagen $1 \%$. Efek analgetik dan antiinflamasi diperoleh pada ekstrak etanol 70\% daun beruwas laut (Scaevola taccada (Gaertn.) Roxb) dengan dosis 12,5 mg/kgBB, 25 $\mathrm{mg} / \mathrm{kgBB}$, dan $37,5 \mathrm{mg} / \mathrm{kgBB}$ yang ditandai dengan jumlah geliatan dan radang pada kaki yang berbeda dengan kelompok kontrol. Hasil analisis statistik menggunakan metode SPSS (Statistical Product and Service Solution) menunjukkan bahwa efek analgetik dan antiinflamasi diperlihatkan oleh Ekstrak etanol 70\% daun beruwas laut (Scaevola taccada (Gaertn.) Roxb). dosis 12,5 $\mathrm{mg} / \mathrm{kgBB}, 25 \mathrm{mg} / \mathrm{kgBB}$, dan $37,5 \mathrm{mg} / \mathrm{kgBB}$ tidak berbeda nyata dengan asam mefenamat dan natrium diklofenak.

\section{Kata kunci : Daun Beruwas Laut, Analgetik, Antiinflamasi.}

\section{PENDAHULUAN}

Salah satu tumbuhan yang sudah dikenal masyarakat sebagai obat analgetik dan antiinflamasi adalah beruwas laut (Scaevola taccada (Gaert.) Roxb.). secara umum beruwas laut digunakan sebagai obat tradisional untuk mengobati diabetes, sakit kepala, infeksi mata, bengkak pada kaki, pegal-pegal, batuk, flu dan lain sebagainya. Adapun kandungan dari tumbuhan beruwas laut (Scaevola taccada (Gaert.) Roxb.). adalah glikosid jenis scaevolin dan satu lagi jenis glikosid lain dari seluruh bagian tumbuhan ini, serta mengandung alkaloid, fenol, dan saponin (Soo, 2009).

Nyeri somatik paling sering muncul pada tubuh kita, sedangkan nyeri viseral dapat bermanifestasi sebagai sakit yang datang dari struktur lainnya atau sebagai fenomena yang lokal (Dipiro \& Talbert, 2009). Analgetik atau obat yang penghilang rasa nyeri adalah zat-zat yang mengurangi 
atau menhalau rasa nyeri tanpa menghilangkan kesadaran (Tjay \& Rahardja, 2007).

Respon pertahanan tubuh terhadap invasi benda asing, kerusakan jaringan, atau keduanya disebut inflamasi. Penyebab inflamasi antara lain mikroorganisme, trauma mekanis, zat-zat kimia, dan pengaruh fisika (Corwin, 2008). Inflamasi adalah usaha tubuh untuk menginkativasi atau merusak organisme yang menyerang, menghilangkan zat iritan, dan mengatur derajat perbaikan jaringan (Mycek dkk., 2013).

Obat antiinflamasi sangat efektif menghilangkan rasa nyeri dan pembengkakan akibat adanya inflamasi dengan menekan produksi prostaglandin dan metabolisme asam arikidonat dengan cara pemhambatan siklooksigenase dan lipooksigenase pada kaskade inflamasi sehingga fungsi otot dan sendi membaik (Setyarini, 2009). Penelitian telah membuktikan bahwa prostadglandin menyebabkan sensitisasi reseptor nyeri terhadap stimulasi mekanik dan kimiawi (Wimana \& Sulistia, 2007).

Obat Analgetik dan Anti-Inflamasi yang ada sekarang memiliki banyak efek samping seperti nyeri lambung. Oleh karena itu dilakukan pencarian obat baru yang berasal dari alam. Obat tradisional tidak memiliki efek samping atau memiliki efek samping yang jauh lebih kecil jika dibandingkan dengan obat sintetik.

Dari hal tersebut, maka tujuan penelitian akan dilakukan pengujian efek analgetik dari tumbuhan beruwas laut (Scaevola taccada (Gaertn.) Roxb.) sebagai alternatif tumbuhan yang berkhasiat sebagai obat.

\section{METODE DAN BAHAN \\ Lokasi Penelitian}

Lokasi Pelaksanaan penelitian di Laboratorium Farmakologi dan Laboratorium Bahan Alam Fakultas Farmasi Universitas Hasanuddin Makassar dan waktu penelitian dimulai pada bulan Maret 2017 sampai selesai.

Desain Penelitian
Rancangan
penelitian $\begin{array}{r}\text { yang } \\ \text { digunakan dalam penelitian ini adalah }\end{array}$

rancangan penelitian eksperimental dengan pendekatan pre-post test only group design.

\section{Variabel Penelitian}

Variabel dependent : Saponin, Dosis

beruwas laut.

Variabel independent : Ekstrak beruwas laut, Asam asetat, Karagen

\section{Populasi dan sampel}

Sampel yang digunakan adalah daun beruwas laut (Scaevola taccada (Gaertn.) Roxb.) diambil dari Desa Wiring Tasi, Kecamatan Suppa, Kabupaten Pinrang, Sulawesi Selatan.

\section{Pengumpulan data}

Pada pengujian analgetik hewan coba diinduksi menggunakan asam asetat $1 \%$ lalu diamati jumlah geliat yang tejadi pada hewan coba tersebut kemudian dicatat, selanjutnya pada pengujian antiinflamasi telapak kaki hewan coba diinduksi menggunakan karaginan 1\% lalu dihitung volume pembengkakan pada telapak kaki hewan coba kemudian dicatat hasilnya.

\section{Analisis Data}

Analisis data dilakukan
menggunakan
menggunakan
dilanjutkan pengujian antar kelompok yaitu
uji Mann-Whitney.

\section{HASIL DAN PEMBAHASAN} Hasil Penelitian

Gambar 1 memperlihatkan jumlah rata-rata geliat Tikus Putih (Rattus norvegicus) Jantan pada uji efek analgetik ekstrak etanol $70 \%$ daun beruwas laut (Sacevola taccada. Gartn.) Roxb).

Tabel 1 dan gambar 2 memperlihatkan persentase proteksi anelgetik pada pengujian efek analgetik yang memperlihatkan bahwa semua ekstrak memiliki efek analgetik yang signifikan bila dibandingkan dengan kelompok (kontrol negatif), dan efek yang tidak jauh berbeda dengan (kontrol positif). Dosis yang efektif sebagai analgetik adalah 7,5 mg/200 gBB.

Tabel 2 dan gambar 3 memperlihatkan persentase volume radang pada kaki tikus pada pengujian efek antiinflamasi yang memperlihatkan bahwa semua ekstrak memiliki efek antiinflamasi 
yang signifikan bila dibandingkan dengan kelompok (kontrol negatif), dan efek yang tidak jauh berbeda dengan (kontrol positif). Dosis yang efektif sebagai antiinflamasi adalah 7,5 mg/200 gBB.

\section{Pembahasan}

Dari pengujian efek analgetik dan antiinflamasi dapatkan hasil ekstrak etanol $70 \%$ daun beruwas laut (Sacevola taccada. Gartn.) Roxb) dengan dosis ekstrak 2,5 $\mathrm{mg} / 200 \mathrm{gBB}, 5 \mathrm{mg} / 200 \mathrm{gBB}$, dan 7,5 $\mathrm{mg} / 200 \mathrm{gBB}$, dapat menurunkan geliat pada tikus yang telah diinduksi dengan asam asetat $1 \%$ serta pada dosis yang sama dapat juga menurunkan volume radang pada telapak kaki tikus yang diinduksi dengan karagen $1 \%$.

Beruwas laut (Scaevola taccada (Gaert.) Roxb.). secara umum digunakan oleh masyarakat sebagai obat tradisional untuk mengobati diabetes, sakit kepala, infeksi mata, bengkak pada kaki, pegalpegal, batuk, flu dan lain sebagainya. Adapun kandungan dari tumbuhan beruwas laut (Scaevola taccada (Gaert.) Roxb.). adalah glikosid jenis scaevolin dan satu lagi jenis glikosid lain dari seluruh bagian tumbuhan ini, serta mengandung alkaloid, fenol, dan saponin (Soo, 2009).

Metode yang digunakan pada pengujian efek analgetik adalah metode induksi kimia digunakan terutama untuk menguji obat analgetik non narkotik yaitu dengan menggunakan senyawa kimia. Rasa nyeri yang disebabkan pemberian induktor nyeri akan menyebabkan timbulnya writhing (geliat) yang dapat diamati sebagai torsi pada satu sisi, menarik kaki ke belakang, penarikan kembali abdomen, kejang tetani dengan membengkokan kepala dan kaki ke belakang (Nugraha, 2011).

Pada penelitian ini hewan coba dibagi menjadi lima kelompok dimana kelompok I diberikan Na.CMC sebagai kontrol negatif. Kelompok II diberikan asam mefenamat sebagai kontrol positif Kelompok III, IV dan V diberikan ekstrak beruwas laut (Sacevola taccada. Gartn.) Roxb) masing-masing (2,5 mg/200gBB), (5 $\mathrm{mg} / 200 \mathrm{gBB})$, dan $(7,5 \mathrm{mg} / 200 \mathrm{gBB})$ diberikan ekstrak dengan konsentrasi yang berbeda. Pemberian obatnya dilakukan secara peroral dan diinduksi dengan asam asetat $1 \%$ secara intraperitonial. Pemberian asam asetat yaitu 30 menit setelah pemberian obat karena diharapkan dalam waktu tersebut telah terjadi absorbsi obat dalam tubuh hewan cobaPenggunaan asam mefenamat sebagai kontrol positif dikarenakan penggunaan obat ini sebagai analgetik sudah cukup umum dalam masyarakat dan efek samping yang ditimbulkan oleh asam mefenamat khususnya dalam mengiritasi saluran cerna masih terbilang rendah jika dibandingkan dengan aspirin (Sukandar dkk., 2008).

Pada perhitungan persen proteksi analgetik dilakukan untuk mengetahui besarnya kemampuan dari ekstrak daun beruwas laut (Sacevola taccada. Gartn.) Roxb) dalam mengurangi rasa nyeri. Persentase proteksi analgetik yang dibandingkan dengan kontrol terlihat bahwa semakin besar dosis ektrak daun beruwas laut yang diberikan maka makin besar pula daya analgetiknya.

Dari hasil uji Kruskal-Wallis dan uji Mann-Whitney pada menit ke-5, 10, 15, 20, 25, dan 30 sudah terlihat ada perbedaan jumlah geliat antara kelompok Na.CMC (kontol negatif) dengan kelompok asam mefenamat (kontrol positif) dan kelompok ekstrak, hal itu dapat dilihat dari perbedaan angka yang cukup jauh pada kolom Mean Rank.

Pengujian efek antiinflamasi metode yang di gunakan adalah Pembentukan Edema Buatan. Metode ini berdasarkan pengukuran volume dari edema buatan. Volume edema diukur sebelum dan sesudah pemberian zat yang di uji. Pengukuran volume udem menggunakan pletismometer dengan prinsip pengukuran berdasar hukum Archimedes yaitu benda yang dimakasukkan kedalam zat cair akan memberi gaya atau tekanan keatas sebesat volume yang dipindahkan.

Bahan pembanding yang digunakan pada penelitian adalah natrium diklofenak. Obat ini merupakan golongan AINS yang mekanisme kerjanya dapat menghambat pembentukan siklooksiginase 2 (COX-2) yang merupakan enzim pemicu terbentuknya prostaglandin (Mediator peradangan) dalam jaringan (Tjay \& Rahardja, 2007). Obat antiinflamasi non steroid (AINS) bekerja dengan elektivitas COX-1 dan COX-2 dapat bervariasi dan tidak lengkap bagi bahanbahan yang lebih lama, tetapi 
penghambatan-penghambatan COX-2 yang sangat efektif sekarang bisa didapat (Katzung, 2007). Natrium diklofenak juga sering digunakan sebagai kontrol pembanding pada penelitian efek antiinflamasi.

Pada proses induksi inflamasi menggunakan karagen karena memiliki beberapa keuntungan antara lain tidak meninggalkan bekas, tidak menimbulkan kerusakan jaringan dan memberikan respon yang lebih peka terhadap obat antiinflamasi dibanding senyawa iritan lainnya (Rowe et al., 2009). Zat ini dapat digunakan untuk memicu terbentuknya udem yang diinduksikan secara subplantar pada telapak kaki tikus (Anggraini, 2008).

$$
\text { Pada perhitungan rata-rata }
$$
persentasi volume radang tertinggi ada pada kelompok Na.CMC, hal itu berarti bahwa volume radang pada kaki tikus kelompok Na.CMC tidak terjadi penurunan, sedangkan pada kelompok Natrium diklofenak dan ekstrak 2,5 mg/200 gBB, $5 \mathrm{mg} / 200 \mathrm{gBB}$, dan $7,5 \mathrm{mg} / 200 \mathrm{gBB}$. terlihat terjadi penurunan persentase volume pembengkakan kaki tiap jamnya.

Dari hasil uji Kruskal-Wallis dan uji Mann-Whitney pada jam ke-1 dan ke-2 belum terdapat perbedaan yang bermakna penurunan volume kaki tikus dari tiap kelompok, sedangkan pada jam ke-3, ke4, dan ke-5 sudah terlihat ada perbedaan angka yang bermakna antara kelompok Na.CMC (kontol negatif) dengan kelompok Natrium diklofenak (kontrol positif) dan kelompok ekstrak.

\section{PENUTUP}

Ekstrak etanol $70 \%$ daun beruwas laut (Sacevola taccada (Gertn).Roxb) pada semua dosis memiliki efek analgetik dan antiinflamasi dan secara statistik memperlihatkan efek yang tidak jauh berbeda dengan efek asam mefenamat dan natrium diklofenak. Dosis yang efektif sebagai analgetik dan antiinflamasi yaitu dosis 7,5 mg/200 gBB. Dari penelitian yang telah dilakukan, disarankan untuk melanjutkan pada pengujian kandungan senyawa bioaktif Saponin ekstrak daun beruwas laut (Sacevola taccada. Gartn.) Roxb). secara kuantitatif untuk lebih memudahkan pada penelitian selanjutnya.

\section{DAFTAR PUSTAKA}

Anggraini W. (2008). Efek Antiinflamasi Ekstrak Etanol Daun Jambu (Psidum guajava Linn.) Pada Tikus Putih Jantan Galur Wistar (Tesis). Surakarta: Universitas Muhammadiyah Surakarta.

Corwin E.J. (2008). Handbok of Pathophysiology $3^{\text {th }}$ Edition. Philadelphia: Lippincort Williams \& Wilkins.

Dipiro T.J. \& Talbert L.R. (2009). Pharmacotherapy A Pathophysiologic Approach $7^{\text {th }}$, edition. United States: Mc Graw Hill Medical.

Katzung B.G. (2007). Basic and Clinical Pharmacology $10^{\text {th }}$ Edition. San Francisco: University of California.

Mycek J.M. dkk. (2013). Farmakologi Ulasan Bergambar edisi IV. Surabaya: Widya Medika.

Nugraha L.S. (2011). Analagetika. Semarang: Akademi Farmasi Theresiana.

Rowe R.C., Paul J.S. \& Marin E.Q. (2009). Handbook of Pharmaceutical Excipients Sixth edition. London: Pharmaceutical Press.

Setyarini H. (2009). Uji Daya Antiinflamasi Gel Ekstrak Etanol Jahe 10\% (Zingiber officinale roscoe) yang Diberikan Topikal Terhadap Udem Kaki Tikus yang Diinduksi Karagenin (Skripsi). Surakarta: Universitas Muhammadiyad Surakarta.

Soo S.Y. (2009). Medical Plants In Papua New Guinea. Western Pacific: WHO Press.

Sukandar dkk. (2008). ISO Farmakoterapi. Jakarta: PT. ISFI Penerbitan.

Tjay T.H. \& Rahardja K. (2007). Obat-Obat Penting Khasiat, Penggunaan, dan Efek-Efek Sampingnya Edisi ke VI. Jakarta: PT Elex Media Komputindo. 
Tabel 1. Persentase proteksi analgetik

\begin{tabular}{lc}
\multicolumn{1}{c}{ Kelompok } & proteksi analgetik $(\%)$ \\
\hline Na.CMC & 0 \\
Asam Mefenamat & 85.73 \\
Dosis $2,5 \mathrm{mg} / 200$ gramBB & 90.29 \\
Dosis $5 \mathrm{mg} / 200$ gramBB & 89.62 \\
Dosis $7,5 \mathrm{mg} / 200$ gramBB & 94.84 \\
\hline
\end{tabular}

Tabel 2. Volume rata-rata persentase radang telapak kaki tikus pada uji efek antiinflamasi

\begin{tabular}{|c|c|c|c|c|c|}
\hline \multirow{2}{*}{ Kelompok } & \multicolumn{5}{|c|}{ rata-rata persentasi radang $(\%)$} \\
\hline & Jam 1 & Jam 2 & Jam 3 & Jam 4 & Jam 5 \\
\hline Na.CMC & 60.50 & 65.22 & 63.00 & 69.22 & 73.22 \\
\hline Natrium Diklofenak & 53.38 & 34.30 & 20.76 & 16.54 & 9.72 \\
\hline ekstrak 2,5 mg/200gramBB & 52.73 & 32.00 & 24.36 & 16.91 & 12.91 \\
\hline ekstrak 5 mg/200gramBB & 62.52 & 50.80 & 44.48 & 34.99 & 30.49 \\
\hline ekstrak 7,5 mg/200gramBB & 57.56 & 38.67 & 28.00 & 17.00 & 10.00 \\
\hline
\end{tabular}

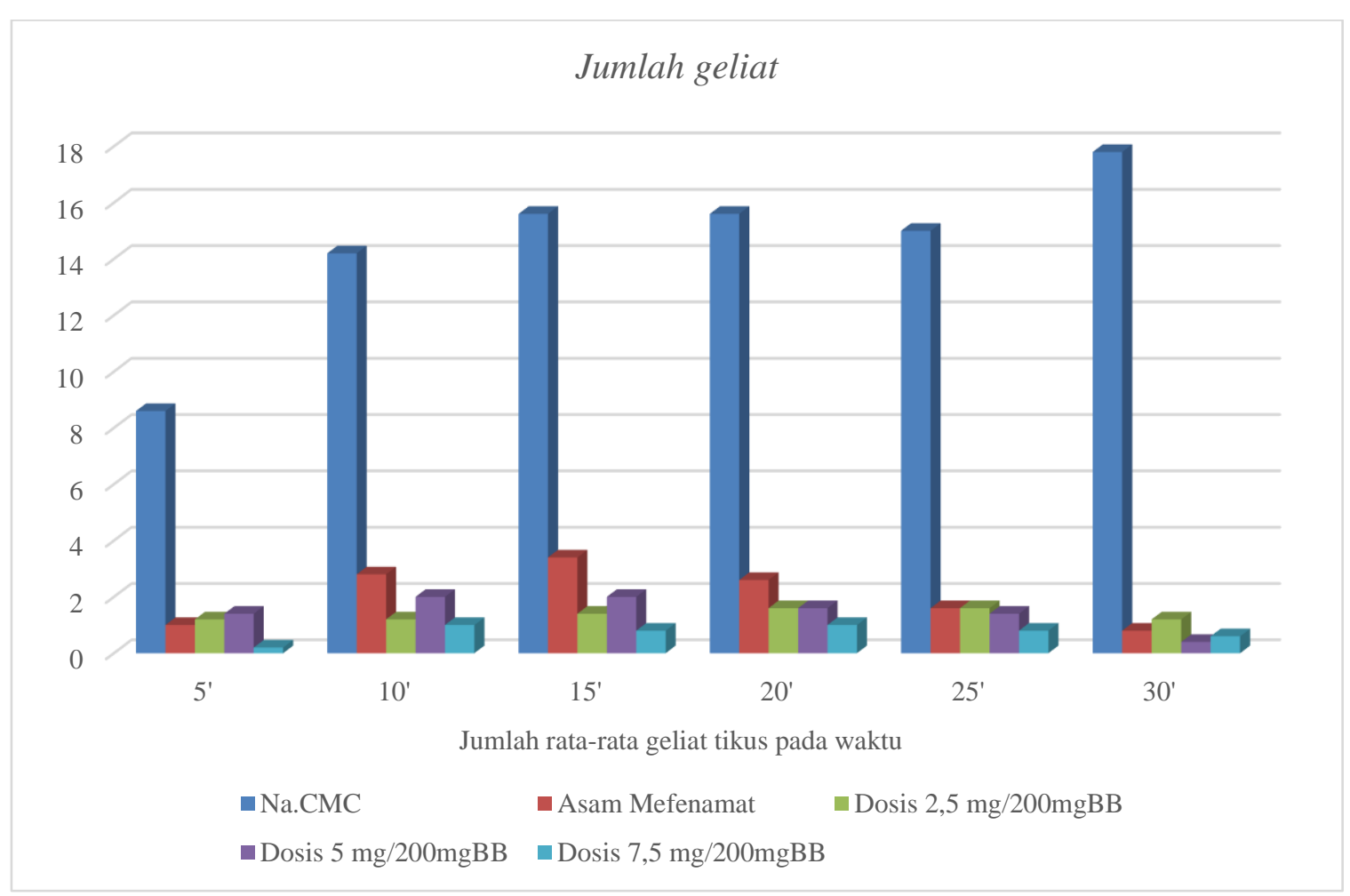

Gambar 1. Rata-rata jumlah geliat pada uji analgetik 


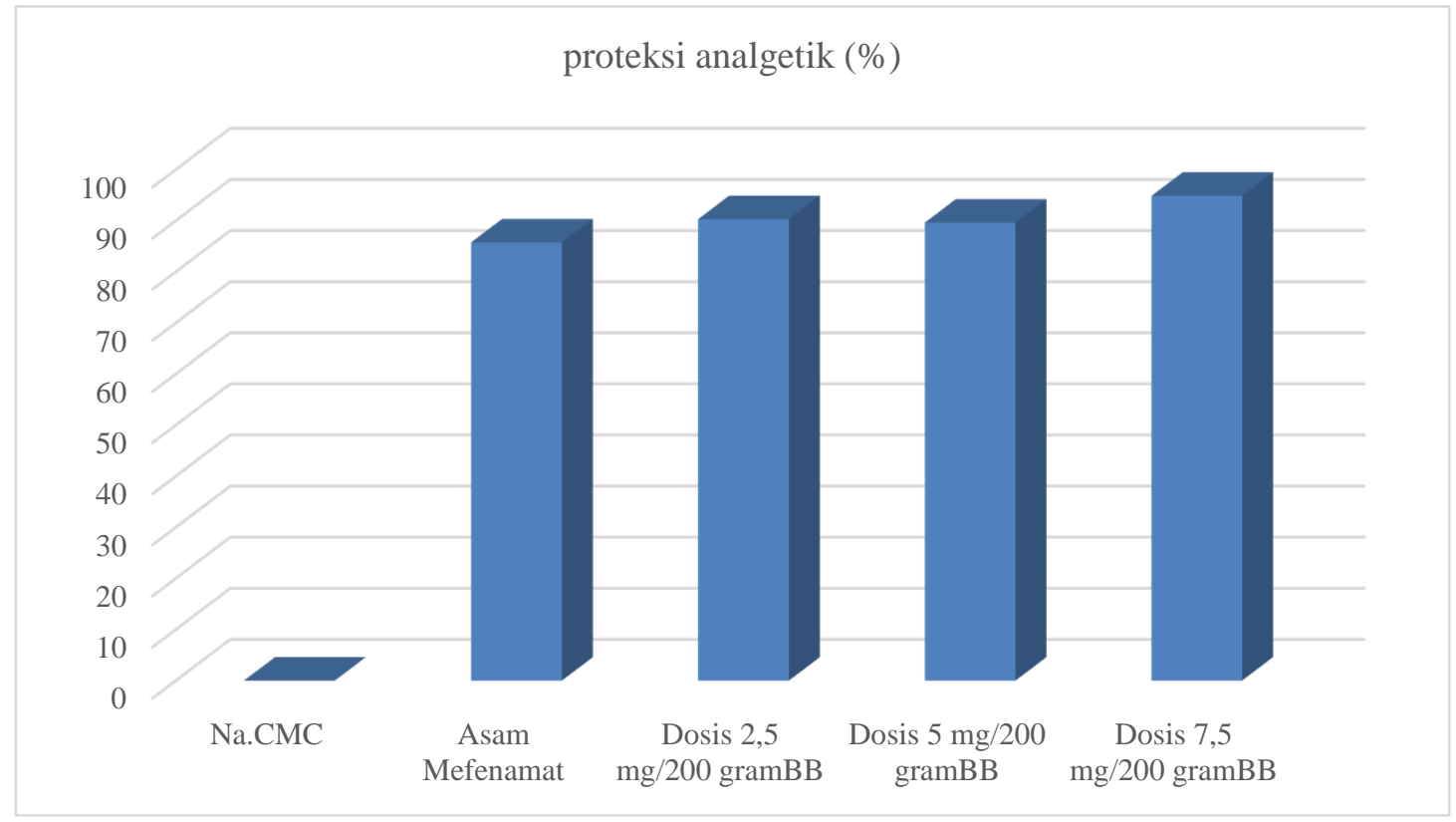

Gambar 2. Persentase proteksi analgetik.

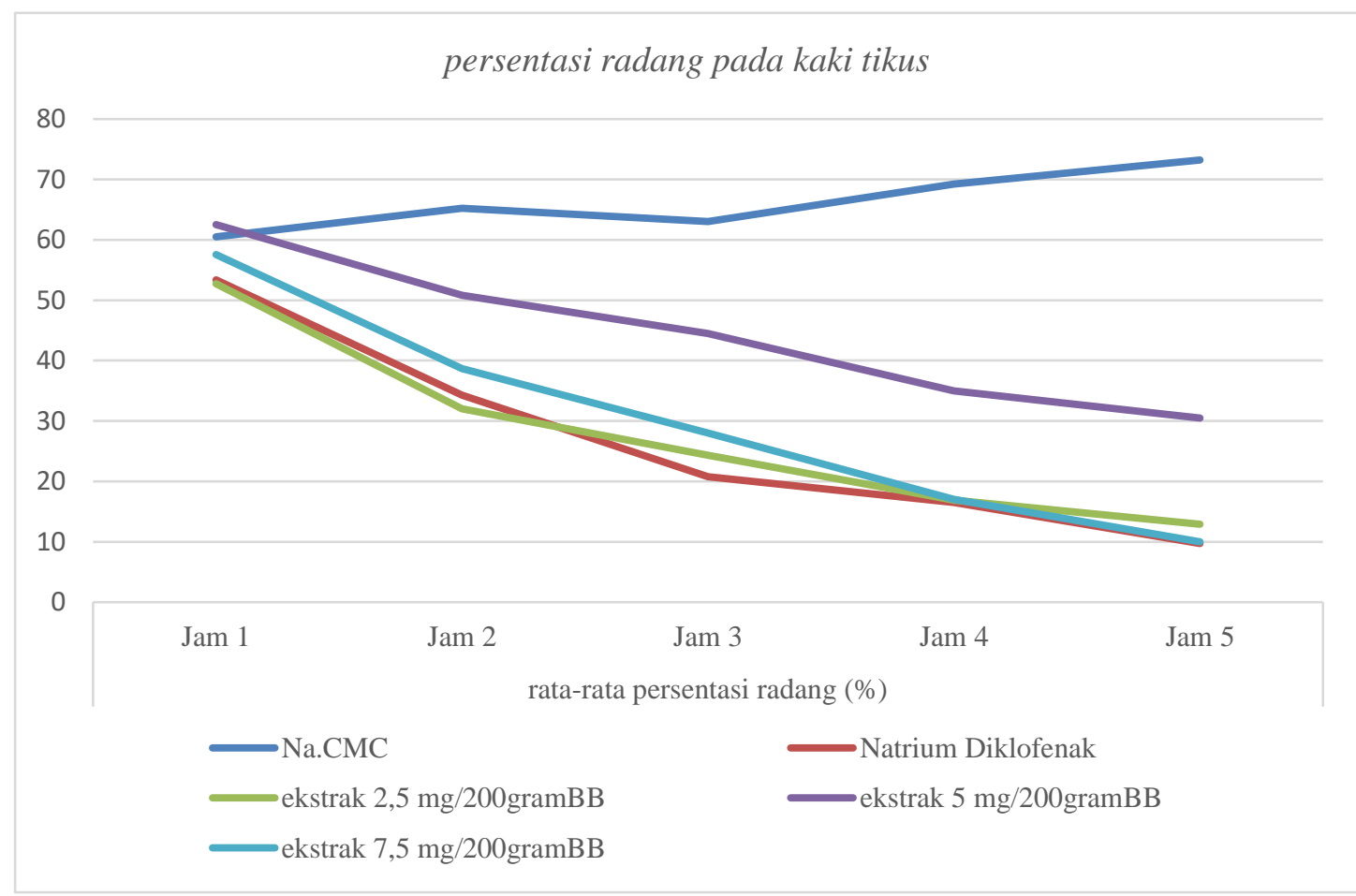

Gambar 3. Volume rata-rata persentase radang telapak kaki tikus pada uji efek antiinflamasi 